\title{
Mennesker og kveg som udetonerte bomber
}

\author{
Gjennom tidene har det vært skrevet tallrike artikler og bøker om tarmgassens mysterier. \\ Dette angår i høyeste grad dagliglivet, men har samtidig viktige globale ringvirkninger.
}

Med god hjelp av alle tarmbakteriene fører nedbrytning av maten til at det avgis gass i tarmen. Mye av gassen består av nitrogen fra nedsvelget luft, og den betyr ikke noe. Det samme gjelder karbondioksid som utskilles i store mengder. Noen gasser er imidlertid illeluktende, og de er ikke helt velkomne i sosialt samvær, særlig ikke i selskapslivet. Men den virkelig farlige gassen er metan. Den er eksplosiv og bidrar til den globale oppvarmingen ved store mengder. Hos et menneske kommer det ut 400-1200 ml tarmgass i løpet av et døgn, avhengig av hva vi spiser. Det ser kanskje ikke så imponerende ut, men det betyr at ved store forsamlinger kan 4000 mennesker slippe ut en hel kubikkmeter med tarmgass bare i løpet av seks timer. Og blir de tilstrekkelig opphisset som for eksempel under en vellykket rockekonsert, kan det bli betydelig større mengder.

Nedenstående artikkel av Hofstad er til skrekk og advarsel. Det er en kasuistikk om en komplikasjon til rektoskopi, som riktignok er sjelden, men desto mer dramatisk når den inntreffer. Moralen er: Visse mennesker er faktisk høyeksplosive i ordets mest konkrete forstand.

Men saken er enda mer alvorlig enn som så. Med økende overbefolkning på jorden får vi to nye og større problemer. For det første blir det sluppet ut enorme mengder tarmgass. For det andre vil de mange menneskene spise tilsvarende mer rødt kjøtt. Det igjen er avhengig av en effektiv kvegavl, og kveg slipper ut astronomiske mengder tarmgass som kan bidra til den globale oppvarmingen. I USA er det dannet egne forenin- ger til bekjempelse av kvegavl på grunn av de store miljøproblemene som dette medfører. Bak enhver fristende rød biff ligger det altså mange kubikkmeter med tarmgass og duver i atmosfæren, med fare for at den globale oppvarmingen akselererer ytterligere. Disse dystre utsiktene kommer i tillegg til den direkte faren for lokale gasseksplosjoner.

Derfor er det viktig å vise ansvar og ikke overdrive verken eget lokalt gassutslipp eller inntak av biff. Men biffinntaket kan også ha positive ringvirkninger, som illustrert gjennom følgende historie:

For en del år siden var jeg på en kongress i Buenos Aires. Første kvelden tok jeg en spasertur i denne store og vakre metropolen. I smågatene krydde det av restauranter som serverte de lekreste kjøttretter basert på pampasens rikholdige kvegbestand. Stort sett var det god plass på spisestedene, men foran ett bestemt steakhouse sto det en lang $k \emptyset$. Jeg gikk bort for å se hva det var. Over inngangen og rett i front av alle de ventende, sultne gjestene hang et stort skilt: «Beefsteak makes good lovers».

\section{Ole Didrik Lærum}

ole.laerum@gades.uib.no

Ole Didrik Lærum (f. 1940) er professor (adj.) ved Københavns Universitet og professor emeritus ved Universitetet i Bergen.

\section{Eksplosjon i endetarmen}

Et smell høres ved endoskopisk fjerning av en rectumpolypp hos en 71 år gammel pasient, og endoskopet drives ut av rectum. Eksplosjon i endetarm er en sjelden, men fryktet komplikasjon ved polyppektomi som kan unngås ved å ta i bruk ny viten fra medisinsk forskning.

Hofstad B. Eksplosjon i tarmen. Tidsskr Nor Lægeforen 2007; 127: 1789-90.

Oppgitte interessekonflikter: Ingen

Se kommentar side 1791 og kunnskapsprøve på www.tidsskriftet.no/quiz

En 71 år gammel kvinne ble henvist til vårt gastrolaboratorium på grunn av et par episoder med frisk rektalblødning, sist to måneder tidligere. For øvrig hadde hun ingen abdominalplager. Hun var tidligere frisk og brukte ikke acetylsalisylsyre, NSAID-preparater eller antikoagulasjon.
Pasienten ble på basis av foreliggende opplysninger satt opp til en rektosigmoidoskopi. Utredningen hos pasienter med frisk rød rektalblødning, spesielt hvis den er rennende, utenpå avføring eller i for- eller etterkant av defekasjon, vil en endoskopisk undersøkelse av rectum og distale colon være tilstrekkelig.
Ved rektosigmoidoskopi, etter tømming med $240 \mathrm{ml} \mathrm{Klyx}$, kom man til $30 \mathrm{~cm}$ innenfor analkanalen, før man måtte stoppe grunnet dårlig tømming lenger proksimalt. Distalt for dette nivået var tømmingen rimelig god, men med enkelte små avføringsrester (fig 1). Noen få centimeter innenfor analkanalen fremkom en stor polypp på ca. 3-4 cm 
i diameter (fig 1), med en basis bedømt til rundt $2 \mathrm{~cm}$ i diameter.

Nesten alle polypper i colon som er over $1 \mathrm{~cm}$ i diameter er adenomatøse, dvs. har potensial til malign utvikling om de ikke fjernes. Ved påvisning av slike polypper må hele tykktarmen undersøkes med total koloskopi, da en tredel av polyppbærere har multiple polypper. Forekomsten av adenomatøse polypper i høyre colon øker også med alderen. Man kunne derfor hos denne pasienten ha ventet med reseksjon av den påviste polyppen til den forestående totalkoloskopien, men vi valgte å fjerne denne med en gang.

Man bestemte seg for en stykkevis (piecemeal) reseksjon av polyppen ved bruk av polyppektomi med slynge og diatermi. Reseksjonen ble gjennomført uten komplikasjoner, inntil polyppen var barbert helt ned. Det fremkom en lett sivblødning fra reseksjonstomten, og man valgte da å svi forsiktig med den foreliggende slyngen.

Klinisk signifikant blødning inntreffer i $0,5-2 \%$ av polyppektomiene, med tall opp til 6,1 \% (1) i litteraturen. Hyppigere inntrer småblødninger som hos vår pasient. Disse vil ofte stoppe spontant, men man vil som regel ønske å sikre seg dette. Det finnes en rekke endoskopiske metoder for å stoppe blødning, som submukøs injeksjon av fortynnet adrenalin, argonplasmakoagulator (APC), klips og såkalt endoloop, en trådslynge som strammes rundt polyppstilken før reseksjon. Den kanskje enkleste metoden ved de minste blødninger er å bruke det man har for hånden, å svi med slyngen.

Vi satte derfor den nesten lukkede slyngen på reseksjonstomten og svidde med diatermi. I neste øyeblikk inntraff et veldig smell og hele endoskopet ble drevet ut av anus. Ved reskopi etter noen minutter fant man ingen tegn til skade i mucosa, og pasienten klaget kun over en lett ømhet $i$ underlivet. Plagene ga seg etter kort tid. Røntgen oversikt abdomen tatt etter undersøkelsen viste ingen tegn til fri luft. Pasienten ble derfor sendt hjem, med beskjed om å kontakte oss ved symptomer. Ved totalkoloskopi en måned senere kunne pasienten fortelle at det ikke hadde kommet til ytterligere besvær. En laktose pusteprøve tatt noe senere viste at hun er metandanner (fig 2).

Det tok litt tid å forstå at vi hadde opplevd en gasseksplosjon i rectum. Hele polyppen ble resecert med slyngen uten problemer, men først da vi brente på reseksjonsflaten, og sannsynlig skapte en liten gnistbue, inntraff antennelsen. Tit alt hell skjedde dette i rectum, slik at gassen kunne evakueres spontant gjennom anus. Lenger opp i tarmen kan slike episoder få fatale konsekvenser, og det er beskrevet dødelig utgang. Ved perfo- rasjon ville pasienten hatt symptomer. Røntgen oversikt abdomen viste at det ikke var fri luft, og pasienten ble derfor ikke innlagt til observasjon, men fikk beskjed om å ta kontakt, dersom symptomer oppsto.

\section{Diskusjon}

Gasseksplosjon er et sjeldent fenomen ved endoskopi. Så vidt vi vet, er dette ikke rapportert i Norge tidligere, selv om det sannsynligvis har skjedd.

Gassene i tarmen kommer fra svelget luft, bakteriell produksjon, kjemiske reaksjoner og absorpsjon fra blodet. $99 \%$ av tarmgass utgjøres av:

- De atmosfæriske gassene (blodgassene): nitrogen $\left(\mathrm{N}_{2}\right)$, oksygen $\left(\mathrm{O}_{2}\right)$ og karbondioksid $\left(\mathrm{CO}_{2}\right)$

- De bakterielt produserte: hydrogen $\left(\mathrm{H}_{2}\right)$, metan $\left(\mathrm{CH}_{4}\right)$ og $\mathrm{CO}_{2}$.

Tre firedeler av gassen i colon er av bakteriell opprinnelse, resten utgjøres stort sett av $\mathrm{N}_{2}$. De eneste brennbare gassene er $\mathrm{H}_{2}$ og $\mathrm{CH}_{4}$. Rundt $33 \%$ av befolkningen har en bakterieflora i avføringen som produserer $\mathrm{CH}_{4}$ (såkalte metandannere), mens over $95 \%$ av befolkningen produserer $\mathrm{H}_{2}$. Flatus kan inneholde opptil $44 \% \mathrm{H}_{2}$ og $34 \% \mathrm{CH}_{4}$. Studier har vist at $\mathrm{H}_{2} \mathrm{i}$ konsentrasjon $4-72 \%$ og $\mathrm{CH}_{4}$ i konsentrasjon $5-15 \%$ er antennbare, hvis oksygenkonsentrasjonen samtidig er over $5 \%$ (2).

Ved alle typer gastrointestinal endoskopi er man avhengig av insufflering av gass, for å utvide tarmen og derved sikrer god visualisering. Standardinsuffleringsgass ved de fleste sykehus er vanlig romluft. Rapporter om gasseksplosjon ved diatermibehandling under koloskopi ble rapportert i 1970- og -80-årene med fatal utgang $(3,4)$. Eksplosjoner betinger tilstedeværelse av oksygen $i$ colon. Normalt er det svært lavt $0_{2}$ partialtrykk i colon. Da luft inneholder $\mathrm{O}_{2}$, er en forutsetning for eksplosjon luftinnblåsningen under koloskopi. Videre kreves det produksjon av $\mathrm{H}_{2}$ eller $\mathrm{CH}_{4}$. Dette er avhengig av substrat og bakterier, som ved ikke helt rengjort tarm i området. Metandannere har en tarmbakterieflora med metanproduserende bakterier som konsumerer praktisk talt all $\mathrm{H}_{2}$ og omdanner dette til $\mathrm{CH}_{4}$. Metandannende bakterier forekommer vesentlig i venstre colonhalvdel, slik at metandannere vil ha en $\mathrm{H}_{2}$-atmosfære i høyre colon og en $\mathrm{CH}_{4}$-atmosfære i venstre colon og i rectum. Siden laktosepusteprøven hos var pasient påviste at hun var metandanner (fig 2), må vi anta at vi opplevde en metangasseksplosjon.

I 1970- og -80-årene ble tarmen før koloskopi tømt med flytende kost og laxantia, eller peroralt med mannitol. Mannitol danner et substrat for tarmbakterier, som kan lede til høy produksjon av $\mathrm{H}_{2}$ og ev.
$\mathrm{CH}_{4}$. I en studie sammenliknet man intrakoloniske gasser hos 20 pasienter som ble undersøkt med koloskopi uten insufflering av gass, og hos 26 pasienter hvor man brukte vanlig luftinsufflering (5). Nesten alle pasienter var blitt tømt med mannitol. Ingen av pasientene med vanlig luftinnblåsning hadde eksplosive nivåer av $\mathrm{H}_{2}$ eller $\mathrm{CH}_{2}$, men nesten alle hadde en $\mathrm{O}_{2}$ - konsentrasjon på over $5 \%$. I gruppen uten luftinnblåsning hadde seks pasienter eksplosivt nivå av $\mathrm{H}_{2}$ eller $\mathrm{CH}_{4}$ og en av dem i tilegg $0_{2}$-konsentrasjon over $5 \%$. Dessuten hadde $20 \%$ av metandannere for høyt nivå av $\mathrm{CH}_{4}$. I en senere studie undersøkte man 30 pasienter som ble tømt med polyetylenglykol (PEG) før koloskopi. Her fant man ingen pasienter med eksplosivt nivå av $\mathrm{H}_{2}$ eller $\mathrm{CH}_{4}$ (6). En like stor gruppe ble tømt med natriumfosfatklyster til sigmoidoskopi, og det ble funnet to pasienter med forhøyet nivå av $\mathrm{H}_{2}$ og en pasient med for høyt nivå av $\mathrm{CH}_{4} \cdot \mathrm{O}_{2}$-konsentrasjonen ble ikke målt i denne studien. Det kan altså tyde på at det ved de moderne tømmingsmetoder til totalkoloskopi sjelden eller aldri blir skapt eksplosive forhold i tarmen. Imidlertid kan dette ikke utelukkes, så lenge $\mathrm{O}_{2}$ tilføres via luftinsufflering.

Vår pasient var tømt med sorbitolklyster, som er det vanligste i Norge før rektosigmoidoskopi, til forskjell fra utlandet. Da sorbitol, i motsetning til PEG og natriumfosfat, kan utgjøre substrat for bakteriegassdanning, vil man teoretisk ha en større risiko for gasseksplosjon med denne tømmingsmetoden.

\section{$\mathrm{CO}_{2}$-insufflering}

Insufflering av karbondioksidgass $\left(\mathrm{CO}_{2}\right)$ istedenfor luft eliminerer faren for eksplosjon ved gastrointestinal endoskopi, fordi $\mathrm{CO}_{2}$-gass ikke inneholder $\mathrm{O}_{2}$ som er obligat for danning av eksplosive gassblandinger i colon. Det finnes imidlertid flere gode grunner for å anbefale $\mathrm{CO}_{2}$-insufflering ved koloskopi. Det er nå veldokumentert at pasienter som får innblåst $\mathrm{CO}_{2} \mathrm{i}$ stedet for luft, har signifikant mindre plager det

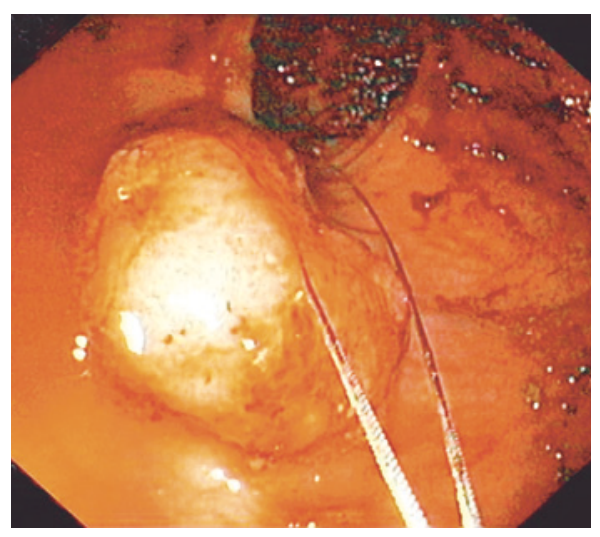

Figur 1 Den bredbasede rectumpolypp før reseksjon 


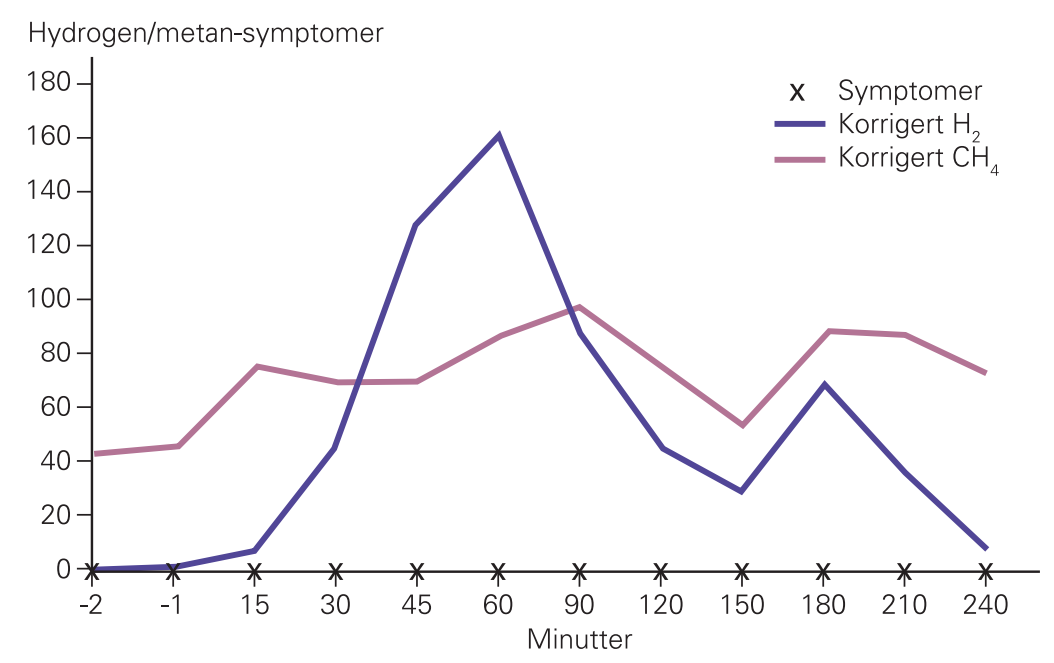

Figur 2 Hydrogen/metan-pusteprøve hos pasienten etter inntak av $25 \mathrm{~g}$ laktose. $\mathrm{H}_{2}$-nivået stiger når substrat når colon, mens $\mathrm{CH}_{4}$-produksjon kun skjer i venstre colon og affiseres ikke av substrattilskudd på høyre side. Vedvarende høyt nivå av $\mathrm{CH}_{4}$ viser at pasienten er metandanner. Stigning i $\mathrm{H}_{2}$-nivået viser at pasienten har en laktoseintoleranse (malabsorbsjon)

neste døgnet etter både sigmoidoskopi (7) og koloskopi (8), og det uten bivirkninger. En time etter koloskopi hadde ca. $45 \%$ av pasientene abdominalt ubehag etter vanlig luftinsufflering, mot $10 \%$ etter $\mathrm{CO}_{2}$-bruk (8). Forklaringen er relativt enkel. Ved en gjennomsnittlig koloskopi insuffleres rundt 81 gass, hvorav kun en del suges ut igjen ved uttrekking av skopet. Absorpsjonen av denne gassen til blod avhenger av partialtrykksforskjellen mellom blod og tarmlumen. Luft inneholder vesentlig $\mathrm{N}_{2}(78 \%)$, som vil gi det samme partialtrykk i blod. Det blir da ingen partialtrykksforskjell, og minimal absorpsjon. Dessuten har blod liten bærekapasitet for $\mathrm{N}_{2}$. Det motsatte gjelder for $\mathrm{CO}_{2}$, som har et lavt partialtrykk i blod, og derfor vil absorberes raskt. Det er påstått at $\mathrm{CO}_{2}$-gass har en halveringstid på to minutter i tarm, mens luft $\left(\mathrm{N}_{2}\right)$ kan forbli i timevis til den kvitteres. Disse gassplagene etter koloskopi kan være svært plagsomme for pasienten. $\mathrm{CO}_{2}$-innsufflering skaper heller ingen problemer for skopøren, idet tarmen er oppblåst lenge nok foran skopet til at man ikke merker forskjell.

\section{Konklusjon}

Risikoen for gasseksplosjon ved bruk av diatermi under koloskopi er liten og avhenger av at det foreligger den rette blanding av eksplosive gasser, noe som i praksis vesentlig i dag vil oppstå ved klystertømming uten helt vellykket rengjøring. $\mathrm{CO}_{2}$-insufflering forhindrer denne eksplosjonsmuligheten. En viktigere grunn til at man vil anbefale $\mathrm{CO}_{2}$-innsufflering, er at dette sparer pasientene for mye luftsmerter etter nedre endoskopi.

\section{Bjørn Hofstad}

bjho@uus.no

Gastromedisinsk avdeling

Ullevål universitetssykehus

0407 Oslo

\section{Litteratur}

1. Yousfi M, Gostout CJ, Baron TH et al. Postpolypectomy lower gastrointestinal bleeding: potential role of aspirin. Am J Gastroenterol 2004; 99: 1785-9.

2. Lev Y El. Explosions during lower bowel electrosurgery. Am J Surg 1954; 88 754-8.

3. Raillat A, de Saint-Julien J, Abgrall J. [ColoniC explosion during an endoscopic electrocoagulation after preparation with mannitol] Gastroenterol Clin Biol 1982; 6: 301-2

4. Bigard MA, Gaucher P. Lassalle C. Fatal colonic explosion during colonscopic polypectomy. Gastroenterol1979; 77: 1307-10.

5. Avgerinos A, Kalantzis N, Rekoumis G et al. Bowel preparation and the risk of explosion during colonscopic polypectomy Gut 1984: 25 : $361-4$

6. Monohan OW, Peluso FE, Goldner F. Combustible colonic gas levels during flexible sigmoidoscopy and colonscopy. Gastrointest Endosc 1992; 38: 40-3.

7. Bretthauer M, Hoff G, Thiis-Evensen E et al. Carbon dioxide insufflation reduces discomfort due to flexible sigmoidoscopy in colorectal cancer screening. Scand J Gastroenterol2002; 37 . 1103-7.

8. Bretthauer M, Thiis-Evensen E, Huppertz-Hauss $G$ et al. NORCCAP (Norwegian colorectal cancer prevention): a randomised trial to assess the safety and efficacy of carbon dioxide versus air insufflation in colonscopy Gut 2002; 50: 604-7.

Manuskriptet ble mottatt 27.1. 2007 og godkjent 1.3. 2007. Redaktør Michael Bretthauer. 